\title{
Implementasi Paradigma Pendidikan Vokasional pada Program Studi Rekam Medis dan Informasi Kesehatan Universitas Gadjah Mada
}

\author{
M. Syairaji ${ }^{1}$, Nur Rokhman ${ }^{1}$, Nuryati $^{1}$ \\ Program Studi D-3 Rekam Medis Sekolah Vokasi, Universitas Gadjah Mada ${ }^{1}$
}

\begin{abstract}
ABSTRAK
Latar Belakang: Pendidikan dan pelatihan vokasional merupakan hal yang penting dalam perkembangan pengetahuan, teknologi dan sosial-ekonomi di negara-negara berkembang seperti Indonesia. Pada bidang sosial-ekonomi, pendidikan vokasional menyediakan akses untuk peningkatan keahlian serta pintu gerbang menuju dunia kerja. Pendidikan vokasional juga dapat dikatakan sebagai jembatan antara pendidikan umum dengan dunia kerja. Rekam medis sebagai salah satu pendidian vokasional seharusnya memiliki tujuan dan paradigma yang sama dengan pendidikan vokasional.

Tujuan: Membandingkan pelaksanaan pendidikan DIII Rekam Medis Sekolah Vokasi UGM dengan konsep/paradigma pendidikan vokasional berdasarkan teori dan referensi.

Metode: Metode penelitian ini adalah literature review dengan menggunakan referensi dari jurnal, UNESCO dan peraturan perundang-undangan.

Hasil: Pelaksanaan pendidikan DIII Rekam Medis telah sesuai dengan paradigma pendidikan vokasional menurut Zarifis, Kotsiki, UNESCO, Permenristek Dikti No.44 tahun 2015 dan No.32 tahun 2016 serta SK Menkes No.377 tahun 2007

Kesimpulan: Secara umum program studi rekam medis UGM telah memiliki kesesuaian dengan tujuan pendidikan vokasional dan sebagai sebuah sistem pendidikan, program studi ini fokus pada mempersiapkan peserta didik menghadapi dunia kerja dengan bekal kompetensi, pengetahuan, sikap yang baik.
\end{abstract}

Kata kunci: Vokasional, edukasi, rekam medis UGM

\begin{abstract}
Background: Vocational education and training is crucial for scientific, technological and socioeconomic development as well as in developing countries such as Indonesia. Especially in social and economic development, it depends on the strength of vocational education as it provides access to skills and entry routes into the labor market. It also could say that vocational education positioned as a hub between general education and the labor market. Medical record education as one of vocational education should have its aims and goals.

Objectives: To compare implementation of medical record study program UGM with vocational education paradigm based on theory and references

Method: This article is literature review that using references form journal, UNESCO and national regulations.

Results: Implementation of medical record study program UGM has met vocational education paradigms according to Zarifis, Kotsiki, UNESCO, Permenristek Dikti No.44 Tahun 2015 and No.32 Tahun 2016 also SK Menkes No.377 tahun 2017.

Conclusion: For the results, overall medical record study program UGM had suited with the aim of vocational education as education system which focuses on preparing students to the working world with certain competencies, knowledge, and attitudes.
\end{abstract}

Key words: vocational, education, medical record UGM 


\section{PENDAHULUAN}

Masyarakat di abad ke-21 ini menghadapi tantangan yang kompleks dan kebutuhan individu yang semakin bertambah. Pendidikan vokasional adalah strata pendidikan yang selalu dinamis seperti perubahan kurikulum yang berdasar pada pertumbuhan pasar kerja dan beradaptasi dengan perkembangan ilmu pengetahuan dan teknologi (Sofyan et al, 2012). Pendidikan vokasional didesain untuk mempersiapkan individuindividu untuk memperoleh pekerjaan atau pekerjaan spesifik yang secara langsung berhubungan dengan produktifitas dan persaingan suatu negara (Lettmayr, 2011).

Berdasarkan Undang-Undang Nomor 20 tahun 2003 tentang Sistem Pendidikan Nasional, program pendidikan tinggi terbagi menjadi tiga aspek yakni pendidikan akademik (sarjana, megister, dan doktoral), pendidikan profesi/spesialisasi, dan pendidikan diploma. Sebelum Peraturan Rektor Nomor 518/P/SK/HT/2008 diimplementasikan, program diploma di Universitas Gadjah Mada berada di bawah masing-masing fakultas. Setelah peraturan tersebut dijalankan, seluruh program diploma dikumpulkan menjadi satu yang disebut dengan Sekolah Vokasi. Program studi rekam medis dan informasi kesehatan merupakan salah satu dari dua puluh tiga program studi yang berada di Sekolah Vokasi UGM. Program studi ini memiliki visi sebagai pioneer pendidikan vokasional di bidang rekam medis dan informasi kesehatan di Indonesia yang bertaraf internasional, unggul, bermartabat, dan juga mampu menghasilkan tenaga kerja professional yang berjiwa pancasila. Tujuan dari telaah literatur ini adalah untuk membandingkan konsep pendidikan vokasional dengan konsep yang diterapkan di program studi rekam medis dan informasi kesehatan Sekolah Vokasi UGM.

\section{DEFINISI PENDIDIKAN VOKASIONAL}

Pendidikan vokasional digunakan sebagai definisi komprehensif yang merujuk pada semua aspek yang terlibat pada proses pendidikan, merupakan tambahan untuk pendidikan umum, proses pembelajaran yang terkait dengan ilmu pengetahuan dan teknologi, memperoleh keterampilan praktis, sikap kerja yang baik, pemahaman serta pengetahuan terkait pekerjaan di segala sektor sosial dan ekonomi (UNESCO, 2001). Menurut Kotsikis (2007), definisi pendidikan vokasional bersifat umum dan termasuk di dalamnya setiap bentuk edukasi yang bertujuan untuk memperoleh kualifikasi-kualifikasi yang terkait dengan profesi tertentu, seni, pekerjaan atau yang menyediakan pelatihan serta keahlian yang diperlukan selain pengetahuan teknis agar nantinya peserta didik mampu menjalankan profesi, seni atau aktifitas, terlepas dari usia dan tingkat pelatihan. Edukasi ini juga mengandung unsure pendidikan umum.

Pelatihan vokasional umumnya didefinisikan sebagai bagian dari pendidikan vokasional yang memberikan pengetahuan dan keterampilan terhadap suatu profesi tertentu. Pelatihan vokasional ini nantinya juga berkontribusi dalam hal kebutuhan peserta didik dan merupakan fokus dari setiap program pelatihan vokasional. Pelatihan vokasionaldapat dilihat sebagai kegiatan atau seperangkat kegiatan yang dirancang untuk mentransmisikan pengetahuan teoritis dan juga keterampilan profesional yang dibutuhkan untuk jenis pekerjaan tertentu (UNESCO, 2001).

Pavlova, (2009) menyebutkan bahwa pendidikan vokasional merupakan pendidikan dengan tujuan utama mempersiapkan individu untuk bekerja menggunakan pendekatan berbasis kompetensi. Pendidikan untuk langsung bekerja memiliki 3 komponen yang saling terkait yakni, pembelajaran untuk bekerja, belajar tentang pekerjaan, dan memahami sifat pekerjaan Sofyan et al, 2012.

\section{INDIKATOR PENDIDIKAN VOKASIONAL}

Sebagaimana yang disebutkan dikebijakan pendidikan, pelatihan vokasional awal terkait dengan penawaran dan permintaan terhadap profesi/pekerja profesional. Penawaran 
dan permintaan ini terbentuk berdasarkan karakteristik struktur ekonomi masingmasing negara (Efstratoglou \& Nikopulou, 2011).Tujuan utama pendidikan vokasional menurut Zarifis (2000) adalah sebagai berikut: 1) Meningkatkan jumlah peserta pelatihan yang telah menyelesaikan pendidikan tingkat menengah tertinggi, 2) Mengembangkan pengetahuan dan keterampilan profesional yang diperlukan untuk praktik profesi, 3) Mengevaluasi tingkat pendidikan peserta, agar mereka bisa menjadi profesional yang kompetitif di masa depan .

Kotsiki (2007) juga mengungkapkan tentang tujuan pendidikan vokasional, yakni: 1) Membantu peserta didik menyesuaikan diri dengan perubahan prosedur produktif, 2) Memberikan pelatihan khusus awal atau lanjutan, 3) Memberikan kebutuhan pasar tenaga kerja secara terus menerus, 4) Mengolah integrasi peserta didik dalam kehidupan profesional dan masyarakat, 5) memberikan kontribusi terhadap perolehan pengetahuan dan keterampilan ekonomi yang dibutuhkan oleh organisasi dan evolusi dari tuntutan profesi, 6) Membantu mengenal kode nilai sosial, integrasi budaya melalui sosialisasi profesional dan penciptaan kode perilaku dan sosial yang merupakan deontologi profesional, 7) Mempersiapkan diri untuk pelaksanaan hak dan kewajiban warga negara sebagai profesional (keamanan, perlindungan, tunjangan sosial, pajak dll.).

Menurut UNESCO (2001), program pendidikan vokasional sebagai persiapan dalam menghadapi dunia kerja harus memiliki berberapa aspek: 1) Bertujuan untuk memberikan pengetahuan ilmiah, keahlian teknis dan serangkaian kompetensi inti serta keterampilan generik yang diperlukan sehingganantinya dapat beradaptasi dengan cepat terhadap gagasan/prosedur baru 2) Didasarkan pada analisis dan perkiraan terkait persyaratan pekerjaan oleh otoritas pendidikan nasional, otoritas ketenagakerjaan, organisasi kerja serta pemangku kepentingan, 3) memasukkan dan terdapat kesesuaian antara mata pelajaran umum, sains dan teknologi, serta mata pelajaran seperti komputer, teknologi informasi dan komunikasi, lingkungan,studi tentang aspek teoritis sertapraktiksesuai dengan bidang pekerjaan, 4) menekankan pengembangan rasa, nilai, etika dan sikap untuk mempersiapkan peserta didik menuju kemandirian, serta tanggung jawab.

Dalam membuat pendidikan vokasional memiliki hasil yang berkualitas, dosen/pengajar juga harus berkualitas dan profesional dalam bekerja. Dosen harus memiliki pemahaman tentang karakteristik pendidikan vokasional seperti mempersiapkan peserta didik memasuki dunia kerja, penyusunan kurikulum salah satunya berdasar pada permintaan pasar, penguasaan kompetensi yang dibutuhkan oleh tempat kerja. Hubungan erat dengan dunia kerja merupakan kunci sukses dalam pendidikan vokasional. Selain itu responsif dan selalu mengantisipasi perkembangan teknologi serta pembelajaran yang berdasarkan pada pengalaman. Proses pengajaran pada pendidikan vokasional juga membutuhkan fasilitas pelatihan yang baik serta memerlukan lebih banyak investasi dan anggaran operasional daripada pendidikan akademis Sofyan et al, 2012.

Menurut Peraturan Menteri Riset, Teknologi, dan Pendidikan Tinggi Republik Indonesia (Permenristekdikti) Nomor 44 Tahun 2015 tentang standar nasional yang harus dipenuhi oleh semua perguruan tinggi, dikatakan bahwa terdapat 8 standar untuk pendidikan tinggi, 1) standar kompetensi lulusan, 2) standar isi pembelajaran, 3) standar proses pembelajaran, 4) standar penilaian pembelajaran, 5) standar dosen dan staf, 6) sarana dan prasarana, 7) standar pengelolaan pembelajaran, dan 8) standar anggaran pembelajaran.

\section{METODE PENELITIAN}

Metode penelitian ini adalah literature review dengan menggunakan referensi dari jurnal, UNESCO dan peraturan perundang-undangan. Pencarian literature sebagian besar dilakukan secara online melalui pencarian google dan situs 
database jurnal. Pencarian literatur menggunakan kata kunci concept, paradigm, and vocational education.

\section{HASIL DAN PEMBAHASAN}

Program rekam medis dan informasi kesehatan sekolah vokasi UGM memiliki misi yakni sebagai pelopor pendidikan terapan di Indonesia dalam bidang Rekam Medis dan Manajemen Informasi Kesehatan yang berkelas dunia, unggul, bermartabat, dan mampu menghasilkan tenaga kerja profesional yang berjiwa Pancasila pada tahun 2025. Untuk mencapai visi tersebut maka disusun 4 misi antara lain sebagai berikut: 1) Menyelenggarakan pendidikan terapan di bidang Rekam Medis dan Manajemen Informasi Kesehatan untuk menghasilkan lulusan yang profesional sesuai tuntutan dunia kerja global. 2) Menyelenggarakan penelitian terapan di bidang Rekam Medis dan Manajemen Informasi Kesehatan guna pengembangan ilmu Rekam Medis dan Manajemen Informasi Kesehatan. 3) Melaksanakan pengabdian kepada masyarakat dan kerjasama dengan para pemangku kepentingan. 4) Menyediakan lingkungan pembelajaran yang kondusif untuk membentuk kepribadian profesional yang memiliki komitmen pengembangan dan penerapan pengetahuan bidang Rekam Medis dan Manajemen Informasi Kesehatan serta pengembangan ketrampilan bagi peningkatan kesejahteraan masyarakat.

Tujuan dari program studi ini adalah:

1) Terselenggaranya pendidikan tinggi terapan bidang Rekam Medis dan Manajemen Informasi Kesehatan yang berkualitas dalam rangka menghasilkan lulusan yang profesional, unggul, kompeten dan bermartabat, yang diakui mutunya oleh dunia kerja nasional maupun internasional. 2) Produk penelitian terapan bidang Rekam Medis dan Manajemen Informasi Kesehatan yang menjadi rujukan nasional yang responsive terhadap permasalahan masyarakat, bangsa, dan negara. 3) Pengabdian kepada masyarakat bidang Rekam Medis dan Manajemen Informasi Kesehatan yang mampu mendorong kemandirian dan kesejahteraan masyarakat secara berkelanjutan. 4) Tata kelola Program Studi Diploma Rekam Medis UGM yang berkeadilan, transparan, partisipatif, dan akuntabel guna menunjang efektifitas dan efisiensi pemanfaatan sumberdaya. 5) Kerjasama yang strategis, sinergis, dan berkelanjutan dengan para mitra (DLIKES SV UGM, 2017).

Jika kita bandingkan tujuan pendidikan vokasional menurut Zarifis (2000), tujuan program studi rekam medis telah sesuai. Salah satu tujuannya adalah meningkatkan jumlah peserta pelatihan dan mengembangkan pengetahuan dan keterampilan profesional telah sesuai dengan tujuan pertama program studi rekam medis yakni menghasilkan lulusan profesional, unggul, kompeten, dan bermartabat yang diakui dalam lingkup dunia kerja nasional maupun internasional. Dalam praktiknya, untuk mencapai hal tersebut, program studi rekam medis membuat kurikulum perkuliahan berdasarkan Peraturan Menteri Kesehatan Nomor 377 tahun 2007 yang membahas tentang kurikulum berbasis kompetensi yang harus dikuasai oleh perekam medis. Untuk mengevaluasi tingkat / kompetensi peserta didik, sebelum lulus mereka harus mengikuti Objective Competence Assessment (OCA) yang diselenggarakan oleh program studi. Tujuan dari tes ini adalah untuk mempersiapkan lulusan dalam mengikuti tes kompetensi profesi yang diselenggarakan oleh PORMIKI sebagai organisasi profesi.

Semua tujuan pendidikan vokasional menurut Kotsiki (2007) juga diimplementasikan dalam program rekam medis UGM. Tujuan pertama, kelima, dan keenam oleh Kotsiki yakni membantu peserta didik dalam menghadapi perubahan prosedur yang produktif, berkontribusi dalam memberikan pengetahuan dan keahlian sesuai dengan tuntutan profesi, memberikan pengetahuan yang sesuai dengan norma dan nilai sosial. Ketiga tujuan ini telah diakomodasi selama proses pembelajaran di kampus. Tujuan kedua, yaitu memberikan pelatihan awal atau lanjutan yang spesifik sesuai dengan bidang profesi telah dilaksanakan dengan cara 
melibatkan dan mengikutsertakan para peserta didik dalam seminar atau pelatihan yang diselenggarakan oleh program studi, PORMIKI, atau APTIRMIKI (pengorganisasian pendidikan tinggi mengenai rekam medis dan informasi kesehatan). Tujuan ketiga, memenuhi kebutuhan pasar tenaga kerja yang terus berubah, telah diimplementasikan dengan PKL (Praktik Kerja Lapangan). Selama 3 tahun proses belajar mengajar di kampus, para peserta didik harus mengikuti 2 kali periode PKL yakni pada akhir semester 2 dan 4 semester di rumah sakit dan Puskesmas untuk mempersiapkan mereka menghadapi dunia kerja sesungguhnya. Pembimbing lapangan kadang memberi saran kepada pengelola program studi jika ada perubahan kebutuhan di tempat kerja. Untuk tujuan keempat, menumbuhkan integrasi dalam kehidupan profesional juga telah dilaksanakan melalui kegiatan PKL. Terkait sumbangsih kepada masyarakat, peserta didik selalu dilibatkan dalam kegiatan pengabdian kepada masyarakat yang diselenggarakan oleh program studi maupun para dosen.

Tujuan pendidikan vokasional menurut UNESCO juga diimplementasikan dalam program studi rekam medis UGM. Untuk tujuan pertama, memberikan pengetahuan ilmiah dan keterampilan kompetensi inti yang dibutuhkan untuk beradaptasi terhadap pengembangan karir yang cepat, kurikulum program studi rekam medis juga berkembang agar sesuai dengan permintaan pasar/user. Tujuan kedua, pendidikan vokasional harus dibuat berdasarkan analisis kebutuhan dan persyaratan oleh otoritas pendidikan nasional, otoritas ketenagakerjaan, organisasi pekerja dan pemangku kepentingan. Hal tersebut juga telah diimplementasikan oleh program studi DIII Rekam Medis Sekolah Vokasi UGM karena dewasa ini rumah sakit dan Puskesmas serta sarana kesehatan lainnya sangat membutuhkan tenaga perekam medis dengan dasar pendidikan rekam medis dan informasi kesehatan. Untuk tujuan ketiga, program studi rekam medis UGM juga telah menerapkan tujuan ini.
Hal tersebut dapat dilihat dari cukup banyaknya mata kuliah yang terkait dengan teknologi informasi. Program studi ini juga memiliki laboratorium komputer untuk mendukung proses pembelajaran. Dan untuk tujuan keempat, etika dan sikap peserta didik juga diperhatikan dilihat dari beberapa mata kuliah yang mempelajari tentang etika dan sikap yang terkait dengan profesi rekam medis.

Menurut Permenristekdikti No. 44 Tahun 2015 standar pertama, lulusan D-III rekam medis UGM telah memenuhi kualifikasi dalam hal indeks prestasi. Dalam lima tahun terakhir, dari 1431 peserta didik yang terdaftar dalam program studi rekam medis, 371 peserta didik adalah lulusan dengan Indeks Prestasi Komulatif (IPK) 3,19 - 3,52. Pada standar kedua, peserta didik dapat lulus dari program studi rekam medis UGM apabila telah menyelesaikan minimal 112 SKS (Satuan Kredit Semester), 59 SKS untuk teori dan 53 SKS untuk praktik. Semua SKS yang diajarkan sudah sesuai dengan standar profesi rekam medis yakni Surat Kepmenkes RI No. 55 / Menkes / SK / III / 2013. Untuk standar ketiga, pembelajaran diimplementasikan dengan menggunakan berbagai strategi dan teknik untuk mendorong peserta didik berpikir kritis untuk mengeksplorasi, berkreasi, dan bereksperimen dengan menggunakan berbagai sumber. Dalam standar keempat, penilaian pembelajaran dievaluasi dalam waktu 5 tahun untuk menyesuaikan diri dengan perkembangan ilmu pengetahuan secara umum dan pengetahuan di bidang rekam medis. Berdasarkan standar kelima yakni ketenagaan, program studi D-III Rekam medis memiliki 24 dosen tetap (1 sarjana, 18 magister, dan 5 gelar doktor dengan 2 orang profesor), 4 dosen temporer (semua dengan gelar magister) dan 9 staf. Standar keenam yakni terkait sarana dan prasarana, program rekam medis memiliki 11 ruang dosen, 1 sekretariat akademik, 1 ruang logistik, laboratorium rekam medis, laboratorium rekam medis elektronik, 10 ruang kuliah dan fasilitas pendukung lainnya. Program rekam medis juga memiliki 86.615 buku teks dan buku pegangan, modul praktik, 
jurnal nasional dan internasional serta prosiding yang dapat diakses oleh peserta didik. Dalam standar ketujuh, pengelolaan pembelajaran rekam medis telah sesuai dengan standar ini yakni terkait perencanaan, pengembangan organisasi, staf, pengawasan, pengarahan, representasi, dan penganggaran. Dan untuk standar terakhir terkait pembiayaan, total dana dalam 3 tahun terakhir lebih dari 4 miliar rupiah setiap tahunnya rupiah berasal dari mahapeserta didik, pemerintah, dan sumber lainnya.

Berdasarkan Permenristek Dikti No. 32 Tahun 2016 yang membahas tentang akreditasi program studi dan pendidikan tinggi, setiap program studi dan pendidikan tinggi harus diakreditasi oleh Badan Akredetasi Nasional Perguruan Tinggi (BAN-PT) untuk menilai kualitas program studi dan pendidikan tinggi. Menurut penilaian akreditasi terakhir pada tahun 2015, program rekam medis UGM terakreditasi A. Hal ini menunjukkan bahwa secara keseluruhan pengelolaan di Program Studi Rekam Medis Sekolah Vokasi UGM memiliki kualitas yang baik sebagai pendidikan vokasional yang menyelenggarakan pendidikan untuk mencetak ahli perekam medis dan informasi kesehatan.

\section{KESIMPULAN}

Secara keseluruhan Program Studi DIII Rekam Medis Sekolah Vokasi UGM telah sesuai dengan tujuan pendidikan vokasional sebagai sistem pendidikan yang fokus mempersiapkan peserta didik ke dunia kerja dengan kompetensi, pengetahuan, dan sikap tertentu. Setiap aspek dan tujuan yang harus ada dalam pendidikan vokasional juga telah dilakukan dan menjadi bagian dari visi, misi, dan tujuan D-III Rekam Medis Sekolah Vokasi UGM.

\section{DAFTAR PUSTAKA}

Departemen Layanan dan Informasi Kesehatan Sekolah Vokasi UGM. (2017). Buku Panduan Akademik 2017/2018 Program Studi Diploma Rekam Medis. UGM: Yogyakarta.

Efstratoglou, A., Nikopulou, B., (2011). Vocational Training as Educational Policy and as Policy for Employment and Labor Market. Vocational Education and Training. Cyprus: Open University of Cyprus.

Kementerian Riset, Teknologi dan Pendidikan Tinggi. (2015). Permenristekdikti No. 44 Tahun 2015 tentang Standar Nasional Pendidikan. Lembaran Negara RI Tahun 2015. Jakarta.

Kementerian Riset, Teknologi dan Pendidikan Tinggi. (2016). Permenristekdikti No. 32 Tahun 2016 tentang Akreditasi Prodi dan PT. Lembaran Negara RI Tahun 2016. Jakarta.

Kotsikis, V. (2007). Educational Administration and Policy. Athens :Ellin.

Lettmayr, C. F., (2011). The Benefit of Vocational Education and Training. European Centre for the Development of Vocational Training. Luxembourg: Publication Office of the Europian Union.

Pavlova. M., (2009). Technology and Vocational Education for Sustainable Development.: Netherlands: Springer Netherlands.

Peraturan Menteri Kesehatan Republik Indonesia No. 55 Tahun 2013 tentang Penyelenggaraan Pekerjaan Perekam Medis.

Republik Indonesia. (2003). Undang-undang No. 20 Tahun 2003 tentang Sistem Pendidikan Nasional. Lembaran Negara RI Tahun 1992. Jakarta.

Sofyan, H, Pardjono, Djatmiko, I. W., Sudira, P. (2012). Paradigma Baru Pendidikan Vokasi. Universitas Negeri Yogyakarta.

United Nation Educational, Scientific, and Cultural Organization, 2001. Revised Recommendation Concerning Technical and Vocational Education and Training. Paris, UNESCO.

Zarifis, G. (2000). Vocational Education and Training Policy Development for Young Adults In The European Union: a Thematic Analysis of the EU Trend of Convergence Towards Integration, Drown From the VET Policies Adopted In Three Member States. Research in Post-Compulsory Education, 5 Sofyan et al, 2012: 91-113. 